\title{
LIST OF JOURNAL AND \\ TEXTUAL ABBREVIATIONS
}

\begin{tabular}{|c|c|}
\hline$A J P$ & American Journal of Philology \\
\hline Anc. Soc. & Ancient Society \\
\hline $\mathrm{C}$ & F. D. Caizzi, ed. Antisthenis Fragmenta. Milan, 1966. \\
\hline$C A$ & Classical Antiquity \\
\hline CJ & Classical Journal \\
\hline$C P$ & Classical Philology \\
\hline$C Q$ & Classical Quarterly \\
\hline$C W$ & Classical World \\
\hline DK & $\begin{array}{l}\text { H. Diels and W. Kranz, eds. Die Fragmente der Vorsokratiker, } \\
\text { 12th ed. Berlin, 1966-67. }\end{array}$ \\
\hline$G \mathcal{E} R$ & Greece $\mathcal{E}$ Rome \\
\hline GRBS & Greek, Roman, and Byzantine Studies \\
\hline HSCP & Harvard Studies in Classical Philology \\
\hline ICS & Illinois Classical Studies \\
\hline$I G$ & Inscriptiones Graeci, 1873-. \\
\hline JHS & Journal of Hellenic Studies \\
\hline $\mathrm{K}-\mathrm{A}$ & R. Kassel and C. Austin, eds. Poetae Comici Graeci. Berlin. \\
\hline LIMC & Lexicon Iconographicum Mythologiae Classicae. Zurich, 1981-. \\
\hline L-P & $\begin{array}{l}\text { E. Lobel and D. L. Page, eds. Poetarum Lesbiorum Fragmenta. } \\
\text { Oxford, } 1955 .\end{array}$ \\
\hline $\mathrm{N}^{2}$ & $\begin{array}{l}\text { A. Nauck, ed. Tragicorum Graecorum Fragmenta, 2nd ed. } \\
\text { Heidelscheim, 1964. }\end{array}$ \\
\hline$N J b$ & Neue Jahrbucher für klassische Altertum \\
\hline$P G$ & $\begin{array}{l}\text { Patrologiae cursus completus, series Graeca, ed. J. P. Migne. } \\
\text { Paris, 1857-66. }\end{array}$ \\
\hline$P M G$ & Poetae Melici Graeci, ed. D. L. Page. Oxford, 1962. \\
\hline Radt & $\begin{array}{l}\text { S. Radt, ed. Tragicorum Graecorum Fragmenta, vol. } 3 \text { (Aeschylus, } \\
\text { 1985), vol. } 4 \text { (Sophocles, 1977). Göttingen. }\end{array}$ \\
\hline REG & Revue des Études Grecques \\
\hline$R h M$ & Rheinisches Museum für Philologie \\
\hline
\end{tabular}


SEG J. J. E. Hondius, ed. Supplementum Epigraphicum Graecum. Leiden, 1923-.

SPh Studia Philologica

Stu. Urb. Studi Urbinati

TAPA Transactions of the American Philological Association

$W^{2} \quad$ M. L. West, ed. Iambi et Elegi Graeci, 2nd ed. Oxford, 1989-92.

YCS Yale Classical Studies 